\title{
Experts' Opinion on the Validation of Socio-Environmental Design \\ Factors (SEDeF) Model as a Residential Neighbourhood Crime Prevention Technique in Nigeria
}

\author{
Sunday Emmanuel Olajide ${ }^{1}$, Mohd Lizam ${ }^{2}$ \\ ${ }^{1}$ Universiti Tun Hussein Onn Malaysia \\ 101 Beg Berkunci, Parit Raja, Batu Pahat, Johor, 86400, Malaysia
}

DOI: $10.22178 /$ pos.25-9

JEL Classification: Z13

Received 20.07.2017

Accepted 24.08.2017

Published online 26.08.2017

Corresponding Author:

Sunday Emmanuel Olajide

gp140026@siswa.uthm.edu.my

(c) 2017 The Authors. This

article is licensed under a

Creative Commons Attribution

4.0 License @) (1)

\begin{abstract}
This article centres on validating a proposed model, socioenvironmental design factors (SEDeF) meant to complement the penal system in the area of combating residential neighbourhood crime within the Nigerian residential estates. The research sought experts' opinion on the desirability and sustainability of the model. Purposive and snow-ball sampling methods were adopted to administer 100 sets of questionnaire out of which 62 were considered usable for the analysis after data screening. SPSS and SEM-AMOS were the key analytical tools adopted to conduct the reliability test, normality test, cumulative mean, exploratory factor analysis (EFA) and the measurement model. The results of the analysis showed that, from the perspectives of the experts, the model is desirable and sustainable for the purpose for which it is proposed (Neighbourhood crime control). The model, if tenaciously implemented is capable of boosting housing values/investment, improve national economy and ensure civic and serene residential neighbourhood.
\end{abstract}

Keywords: experts' opinion; measurement model; residential neighbourhood crime; SEDeF model; validation.

\section{INTRODUCTION}

The importance of residential property (housing) to mankind cannot be underestimated. Apart from providing living accommodation, it could serve as a source of investment which in no small measure could influence the prosperity of a given economy [2]. Hence, any negative influence on housing in the form of residential neighbourhood crime (property crime) should be a concern not only for researchers but also for government and practitioners alike. As a matter of fact, property crime is soaring globally [12] and this over time had called for a paradigm shift in crime control technique especially from the penal system to a better technique. It is in the light of this that the authors of this article proposed in their earlier research a model titled socio-environmental design factors (SEDeF) as a modern and more efficient residential neighbourhood crime prevention strategy based on Nigeria situation.
The thrust of the model dwells on the premise that a conceptual marriage between crime prevention through environmental design (CPTED) and crime prevention through social development (CPSD) would produce better result in crime prevention [19].This concept has been tested and seen to be working in countries like Canada, United States of America, United Kingdom, Australia and few other countries in Europe and Asia [16]. CPTED as a concept believes that a purposeful manipulation of residential developments through design is capable of discouraging prospective offenders. The elements of CPTED include access control, activity support, territorial functioning and natural surveillance among others $[9,17]$. CPSD on the other hand believes that a sincere and concerted effort in tackling the crime risk factors like unemployment, illiteracy, homelessness, family disintegration, juvenile delinquencies and poverty among others which literature identify to be the root causes of crime, 
through effective social development programmes is capable of stemming down crime rate if not eliminating criminal tendencies [21, $23,25]$.

In order to validate the potency of this proposed model, this particular research was embarked upon and it centred on seeking experts' opinion on the efficiency and sustainability of socioenvironmental design factors (SEDeF) model as a veritable crime prevention strategy within the Nigerian residential neighbourhoods.

Hence, in line with the objective of the study, this paper consists of five sections. Section one treats general introduction to the study with reference to relevant literature. The section two describes the methodology adopted for the study, whereas section three presents the data analysis and results. Section four discusses the results of the analysis, Section five concludes the paper, as well as presenting the limitation of the study and further research.

\section{MATERIALS AND METHODS}

In line with the purpose of this research, that is, to seek experts' opinion on the applicability and sustainability of socio-environmental design factors (SEDeF) model as a compliment, if not substitute, to the penal system in the area of residential neighbourhood crime prevention, a structured questionnaire made up of 5-Likert scale design centering on the sustainability of the model (SUS), relevance of the model to the national economy (SNE), SEDeF and residential neighbourhood crime (SRNC) as well as the relationship between SEDeF and residential property values (SRPV). The measurement instrument passed through data screening which included missing values/data, reliability test, normality test and expository factor analysis (EFA). The refined data were later subjected to validity tests (discriminant and convergent) in order to build a fitted measurement model. As a way of introducing the thrust of the model SEDeF to the selected experts, a two page write-up was attached to the questionnaire.

The analysis of the data was initially based on 100 sets of questionnaire rolled out, out of which 76 were retrieved and 62 passed the screen test and were found usable for the analysis. The respondents covered senior academic and practicing professionals in the field of real estate, housing, urban and regional planning, legal practice and senior government officials. Purposive and snow-ball sampling techniques were adopted due to the nature of the respondents. The respondents were selected from academic institutions, government offices and private practice within the south-western Nigeria where the initial research was carried out.

Considering the uniqueness of the research, most of the questions were formulated by the researchers with reference to existing literature. The 5-Likert scale adopted the two extreme agreements, that is, strongly disagree to strongly agree. The findings were based on the existing benchmark setting for each stage of the analysis upon which the conclusions of the research were drawn.

\section{RESULTS AND DISCUSSIONS}

\section{Data analysis process: Introduction}

Prior to the process of data analysis, the data collected from the respondents were coded and entered into statistical package for social science (SPSS) version 22 in order to prepare the data for analysis process. Also, the missing data were considered as missing values. Established codes were employed to assign numbers for each respondent answer, thus, enable the transference of the data from the usable questionnaire collected to SPSS.

In summary, after data were entered into the SPSS data file, data screening processes were conducted. These were to identify errors such as out of range values and omitted entries in the process of data entering. Therefore, original questionnaire were used to correct all the identified errors before the commencement of the appropriate data analysis process for this research. Next were the assessment of normality and reliability of the data collected.

SEM-AMOS which incorporates the factor analyses was adopted being a relatively modern multivariate analytical tool which has been recommended to measure relationships among variables [3]. Its diverse means of reaching research conclusions make it preferable.

\section{Assessment of normality}

Z. Awang [3] asserted that assessment of a scale data is commonly assessed to determine normality of the data distribution. The reason is that 
both factor analysis and structural equation modelling require variables to be normally distributed. More so, distributions of data that is highly skewed or with high kurtosis suggest nonnormality and this implies that there may be presence of outlier cases which resultantly affects the estimation. J. Pallant [20] stated that distribution of variables needs to be checked before using them in the analysis process.

In addition, this research checked for the outliers in the data distribution scores by examining the normality probability plots (Normal Q-Q plot) and the results showed that there was no serious divergence from the normality. In addition, data distribution box plot were checked and 14 outliers were identified out of the 76 useable re- spondents (cases) in the data distribution. Therefore, upon the completion of the descriptive analysis, only 62 respondents (cases) were used for the multivariate research statistical analyses.

J. Pallant [20] recommended that the skewness and kurtosis values of -1 to +1 are considered a symmetry distribution which are suitable for parametric tests and presume a normal distribution. In this regards, the absolute value of skewness and kurtosis for the entire constructs in this research were presented in Tables 1-4 to establish that they are within the recommended ranges. This implied that data distribution for this research satisfied univariate normality. Therefore, additional modification of the data was not needed.

Table 1 - Descriptive statistics for the experts' perception of SEDeF and the national economy (SNE)

\begin{tabular}{|l|l|r|r|r|}
\hline \multirow{2}{*}{ Code } & \multicolumn{1}{|c|}{ Item' Description } & Mean & \multicolumn{1}{c|}{ Skewness } & \multicolumn{1}{c|}{ Kurtosis } \\
\cline { 3 - 5 } & & Statistics & Statistics & \multicolumn{1}{c|}{ Statistics } \\
\hline SPGG & SEDeF can promote good governance & 3.56 & -.543 & -.424 \\
\hline SCIN & SEDeF is capable of curbing incivility & 3.55 & -.504 & -.741 \\
\hline SRPS & SEDeF reduces public spending & 3.50 & -.498 & -.630 \\
\hline SEPR & SEDeF enhances public revenue & 3.55 & -.571 & -.605 \\
\hline SRNP & SEDeF lessens neighbourhood policing & 3.55 & -.592 & -.382 \\
\hline SGFEP & SEDeF good for economic prosperity & 3.65 & -.584 & -.346 \\
\hline SIMC & SEDeF is more civil & 3.58 & -.600 & -.454 \\
\hline
\end{tabular}

In Table 1, the mean, skewness and kurtosis values of the entire items for the respondents' understanding of the relevance of SEDeF model to the national economy were presented. The cu- mulative mean value for the construct on a 5 Likert scale was 3.562 and this indicated that experts have good perceptions of the relevance of SEDeF model to the national economy.

Table 2 - Descriptive statistics for the experts' perception of the sustainability of SEDeF model (SUS)

\begin{tabular}{|l|l|r|r|r|}
\hline \multirow{2}{*}{ Code } & \multicolumn{1}{|c|}{ Item' Description } & Mean & \multicolumn{1}{c|}{ Skewness } & \multicolumn{1}{c|}{ Kurtosis } \\
\cline { 3 - 5 } & & Statistics & Statistics & \multicolumn{1}{c|}{ Statistics } \\
\hline PSSS & Political structure will support SEDeF & 3.68 & -.672 & -.226 \\
\hline BAFS & Cost-Benefit analysis favours SEDeF & 3.60 & -.595 & -.479 \\
\hline SESS & Socio-economic supports SEDeF & 3.77 & -.830 & .059 \\
\hline SPSI & SEDeF will enjoy public support to implement & 3.56 & .131 & -.576 \\
\hline SIBN & SEDeF implementation will benefit Nigerians & 3.63 & -.610 & -.365 \\
\hline SSSO & SE\$DeF can be sustained over time & 3.60 & -.595 & -.497 \\
\hline SBEP & SEDeF brings economic profitability & 3.47 & -.521 & -.362 \\
\hline SEMP & SEDeF brings environmental profitability & 3.69 & -.691 & -.334 \\
\hline GASF & There will be general acceptability for SEDeF & 3.66 & -.669 & -.417 \\
\hline
\end{tabular}

In Table 2, the mean, skewness, kurtosis and values of all the items of measurement for the sustainability of SEDeF model as scored by the experts from within the relevant professions were presented. The cumulative mean value for the SEDeF sustainability was 3.629 on a 5-Likert scale and this indicated that the experts believed in the sustainability of SEDeF model as a veritable neighbourhood crime prevention technique. However, research finding made known that socio-economic capacity of Nigeria as a nation will support the implementation of SEDeF which scored highest mean (3.70). 
Table 3 - Descriptive statistics for the experts' perception of the relationship between SEDeF and residential property values (SRPV)

\begin{tabular}{|l|l|r|r|r|}
\hline \multirow{2}{*}{ Code } & \multicolumn{1}{|c|}{ Item' Description } & Mean & \multicolumn{1}{c|}{ Skewness } & \multicolumn{1}{c|}{ Kurtosis } \\
\cline { 3 - 5 } & & Statistics & Statistics & \multicolumn{1}{c|}{ Statistics } \\
\hline SDHV & SEDeF determines housing values & 3.68 & -.672 & -.226 \\
\hline SPREP & SEDeF promotes real estate practice & 3.60 & -.595 & -.497 \\
\hline SCND & SEDeF curbs neighbourhood decline & 3.68 & -.693 & -.292 \\
\hline SBHI & SEDeF boosts housing investment & 3.71 & -.591 & -.424 \\
\hline SDRM & SEDeF discourages residential mobility & 3.69 & -.669 & -.274 \\
\hline SIHV & SEDeF increases housing values & 3.55 & -.504 & -.741 \\
\hline SCNS & SEDeFcurbs neighbourhood stigmatization & 3.65 & -.353 & -.714 \\
\hline
\end{tabular}

In Table 3, the mean, skewness and kurtosis values of the entire items for the respondents' understanding of the relationship between SEDeF model and residential property values were presented. The cumulative mean value for the con- struct on a 5-Likert scale was 3.650 and this indicated that experts have good perceptions of the relationship between SEDeF model and residential property values.

Table 4 - Descriptive statistics for the experts' perception of the relationship between SEDeF and residential neighbourhood crime (SRNC)

\begin{tabular}{|l|l|r|r|r|}
\hline \multirow{2}{*}{ Code } & \multicolumn{1}{|c|}{ Item' Description } & Mean & Skewness & \multicolumn{1}{c|}{ Kurtosis } \\
\cline { 3 - 5 } & & Statistics & Statistics & \multicolumn{1}{c|}{ Statistics } \\
\hline SSDB & SEDeF stems down burglary & 3.68 & -.672 & -.226 \\
\hline SCI & SEDeF controls incivility & 3.60 & -.595 & -.497 \\
\hline SDPPC & Social development programs cures crime & 3.68 & -.693 & -.292 \\
\hline SNCPS & SEDeF, a veritable crime prevention technique & 3.71 & -.591 & -.424 \\
\hline VSCPS & Virtual house curbs property crime & 3.69 & -.669 & -.274 \\
\hline SCCRF & SEDeF cures crime risk factors & 3.55 & -.504 & -.741 \\
\hline EDCPS & Environmental design curbs property crime & 3.65 & -.353 & -.714 \\
\hline
\end{tabular}

In Table 4, the mean, skewness, kurtosis and values of all the items of measurement for the relationship between SEDeF model and residential property values as scored by the respondents were presented. The cumulative mean value for the residential neighbourhood crime was 3.567 on a 5 -Likert scale and this indicated that the respondents believed in the relationship between SEDeF model and residential neighbourhood crime. However, research finding made known that 'SEDeF as a veritable crime prevention technique scored highest mean (3.71) while SEDeF as a cure to the crime risk factors scored least mean value (3.55). Nonetheless, it is obvious that this research outcome infers that experts support the relationship between the SEDeF and residential neighbourhood crime (RNC) which corresponded with [22] and [24] research findings.

\section{Reliability assessment}

Reliability is the degree to which research measurement are free from random error and the ex- tent to which a scale used produces consistent results if repeated measurements were made on the variable concern $[10,20]$. This implies that reliability and error are related and that the larger the error, the smaller the reliability of the research measurement or vice-versa. As a result, the reliability of the total scale of every constructs in this research was examined to ascertain their internal consistency. J. Pallant [20] recommended that Cronbach's alpha values above 0.7 are considered appropriate and acceptable, even though, above 0.8 are preferable.

Table 5 presents the reliability analysis result for SEDeF and National Economy (SNE), Sustainability of SEDeF (SUS), SEDeF and Residential Neighbourhood Crime (SRNC); SEDeF and Residential Property Values (SRPV). The Cronbach alpha for SNE, SUS, SRNC and SRPV are 0.800, $0.778,0.875$ and 0.866 respectively. These values exceeded 0.70 indicating that the items are reliable for measuring the respective constructs [20]. 
Table 5 - Reliability Analysis

\begin{tabular}{|c|c|c|}
\hline Factors/Constructs & Items & $\begin{array}{c}\text { Cronbach } \\
\text { alpha }\end{array}$ \\
\hline $\begin{array}{l}\text { SEDeF and National } \\
\text { Economy (SNE) }\end{array}$ & $\begin{array}{l}\text { SPGG, SCIN, } \\
\text { SRPS, SEPR, } \\
\text { SGFEP and } \\
\text { SIMC }\end{array}$ & 0.800 \\
\hline $\begin{array}{l}\text { Sustainability of } \\
\text { SEDeF (SUS) }\end{array}$ & $\begin{array}{l}\text { PSSS, SESS, } \\
\text { SIBN, SBEP, } \\
\text { SENP and GASF }\end{array}$ & 0.778 \\
\hline \begin{tabular}{|l} 
SEDeF and \\
Residential \\
Neighbourhood \\
Crime (SRNC) \\
\end{tabular} & $\begin{array}{l}\text { SSDP, SDPPC, } \\
\text { SNCPS, VSCPS, } \\
\text { SCCRF AND } \\
\text { EDCPS }\end{array}$ & 0.875 \\
\hline \begin{tabular}{|l|} 
SEDeF and \\
Residential \\
Property Values \\
(SRPV)
\end{tabular} & $\begin{array}{l}\text { SDHV, SPREP, } \\
\text { SCND, SBHI, } \\
\text { SDRM, SIHV, } \\
\text { and SCNS } \\
\end{array}$ & 0.866 \\
\hline
\end{tabular}

\section{Exploratory Factor Analysis}

Exploratory factor analysis (EFA) is generally employed in the multivariate statistical analysis to select set of items from a large pool of group into a manageable form. This is simply termed data reduction process in the statistical analysis. The purpose is to examine the relationships among the variables prior the application of the confirmatory factor analysis [18, 20]. However, Z. Awang [4] argued that exploratory factor analysis cannot assess unidimensionality directly, in fact, EFA is commonly used to assess the factor structure of a scale. However, J. Hair [13] reported that confirmatory factor analysis (CFA) is a more reliable method for use in a research model where hypotheses about relatively new constructs of variables exist such as the case of this research's proposed Socio-Environmental Design Factors (SEDeF) model. In this regards, the EFA for this research and EFA final result is presented in Table 6.

The 30 items of the four constructs measuring the validation of the sustainability of SEDeF model assessment scales were subjected to exploratory factor analysis using SPSS version 22 out of which 30 items passed the data reduction process. Prior to performing EFA, the suitability of data for factor analysis was assessed and satisfactory.

Inspection of the correlation matrix showed the presence of several coefficients of minimum of 0.5 .
Table 6 - Exploratory factor analysis for the research constructs

\begin{tabular}{|l|c|c|c|c|}
\hline \multirow{2}{*}{} & \multicolumn{4}{|c|}{ Rotated Component Matrix } \\
\cline { 2 - 5 } & 1 & 2 & 3 & \multicolumn{1}{l|}{} \\
\hline SPGG & & & & .776 \\
\hline SRPS & & & & .616 \\
\hline SEPR & & & & .643 \\
\hline SGFEP & & & & .718 \\
\hline SIMC & & & & .565 \\
\hline SDHV & & & & \\
\hline SPREP & & & .720 & \\
\hline SCND & & & .812 & \\
\hline SBHI & & & .863 & \\
\hline SDRM & & & .852 & \\
\hline SIHV & & & .689 & \\
\hline SCNS & & & .853 & \\
\hline & & & & \\
\hline SESS & & .774 & & \\
\hline SIBN & & .668 & & \\
\hline SBEP & & .599 & & \\
\hline SENP & & .862 & & \\
\hline GASF & & .689 & & \\
\hline SDPPC & .900 & & & \\
\hline SNCPS & .930 & & & \\
\hline VSCPS & .497 & & & \\
\hline SCCRF & .785 & & & \\
\hline EDCPS & .893 & & & \\
\hline SSDB & .798 & & & \\
\hline
\end{tabular}

In addition, Kaiser-Meyer-Olkin value score was 0.725 which exceeded the recommended value of 0.6 [14] reached statistical significance, supporting the factorability of the correlation matrix (Table 7).

Table 7 - KMO and Bartlett's Test

\begin{tabular}{|l|l|r|}
\hline \multicolumn{2}{|l|}{$\begin{array}{l}\text { Kaiser-Meyer-Olkin Measure of } \\
\text { Sampling Adequacy }\end{array}$} & .725 \\
\hline $\begin{array}{l}\text { Bartlett's Test of } \\
\text { Sphericity }\end{array}$ & $\begin{array}{l}\text { Approx. Chi- } \\
\text { Square }\end{array}$ & 894.862 \\
\cline { 2 - 3 } & df & 300 \\
\cline { 2 - 3 } & Sig. & .000 \\
\hline
\end{tabular}

\section{Measurement Model}

The use of structural equation modeling (SEM) in analyzing the data through AMOS 21.0 software required a two-step approach which was employed as a pre-requisite for the use of SEM [3]. The first step required the preparation of the 
measurement model estimated for the purpose of confirmatory factor analysis (CFA) with the principal aim of checking the model fit and validity. The goodness of fit is in agreement with the laid down principles. Findings as presented in Figure 1 show that the factor loadings after necessary deleting were found to be significant.

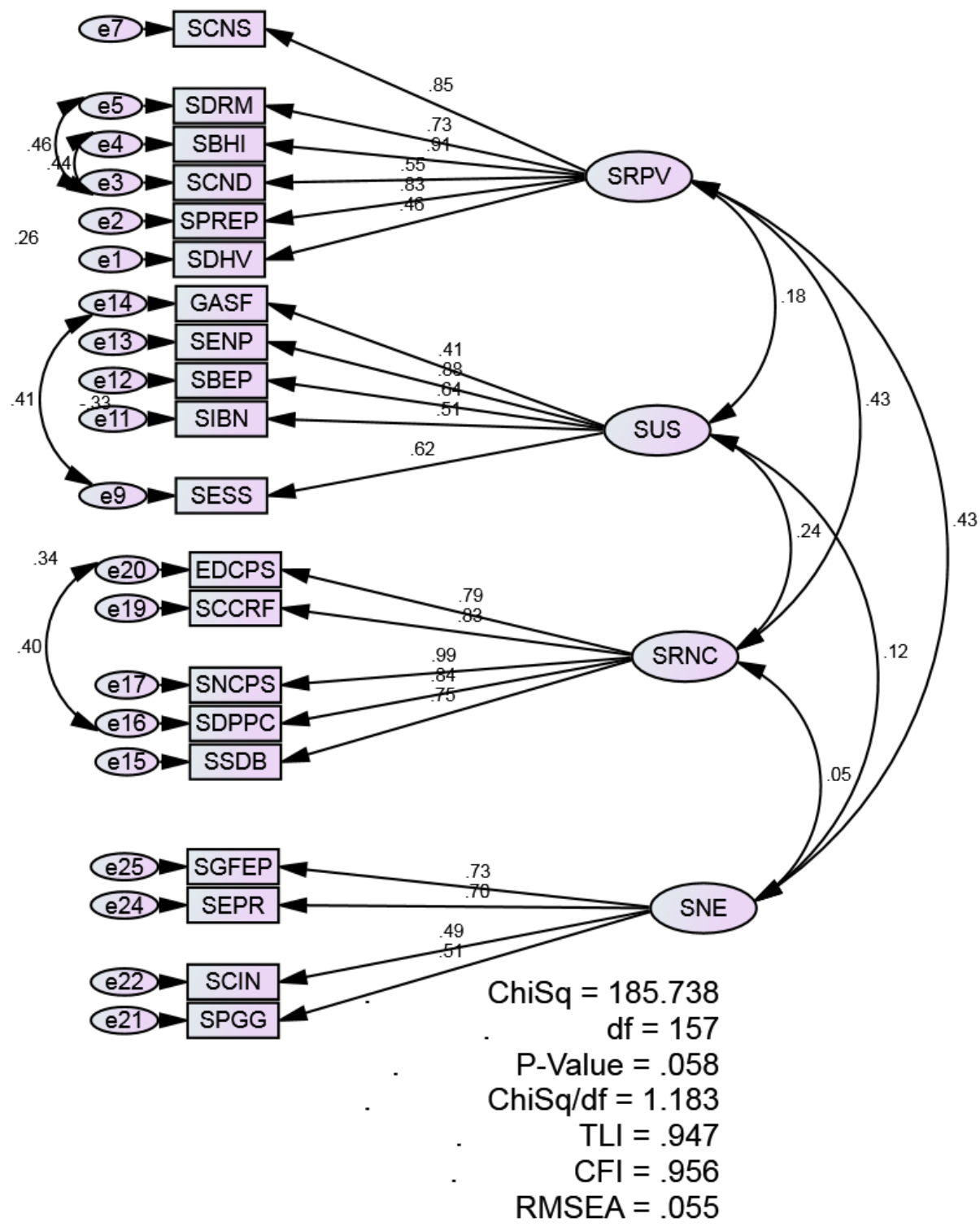

Figure 1 - The measurement Model

That is, not less than $0.5[4,13]$; the chisquare/df stood at 1.183 which is less than the benchmark of < 5.0 [15]; CFI is 0.956 [6]. TLI is 0.947 [7]; RMSEA (root mean square error of approximation is 0.055 which is less than the benchmark of $\leq 0.080$ [8]. In summary, these result figures meet all the recommended criteria for the good model fit $[3,5,13]$.

To ensure that the model is properly fit, the data were also tested for construct validity which involved the discriminant and convergent validity as well as the correlation matrix for the entire research constructs $[4,13]$.
Discriminant validity is achieved when the square root of the Average Variance Extracted (AVE) is greater than the correlation with other constructs [13]. The loadings of all reflective indicators are above 0.5 (being new measurement instrument) after the data had been refined through reliability test (Cronbach alpha) and expository factor analysis (EFA). The values of composite reliability for all reflective constructs are above $0.7[3,13]$ and the AVE for each construct is above 0.40 [11] confirming a convergent validity as shown in Tables 8-9. 
Table 8 - The summary of measurement Model

\begin{tabular}{|l|l|r|c|r|}
\hline Construct & Items & Loadings & CR & AVE \\
\hline SNE & SPGG & 0.51 & 0.82 & 0.44 \\
\hline & SCIN & 0.50 & & \\
\hline & SRPS & 0.70 & & \\
\hline & SGFEP & 0.73 & & \\
\hline & SESS & 0.62 & 0.83 & 0.47 \\
\hline & SIBN & 0.51 & & \\
\hline & SBEP & 0.64 & & \\
\hline & SENP & 0.88 & & \\
\hline SRPV & GASF & 0.41 & & \\
\hline & SDRM & 0.73 & 0.84 & 0.52 \\
\hline & SBHI & 0.91 & & \\
\hline & SCND & 0.55 & & \\
\hline & SPREP & 0.83 & & \\
\hline & SDHV & 0.50 & & \\
\hline SRNC & SCNS & 0.85 & & \\
\hline & SSDB & 0.63 & 0.92 & 0.70 \\
\hline & SDPPC & 0.65 & & \\
\hline & SNCPC & 0.75 & & \\
\hline & SCCRF & 0.83 & & \\
\hline & EDCPS & 0.79 & & \\
\hline
\end{tabular}

Note:

a) Composite Reliability (CR) = (square of the summation of the factor loadings) / \{ (square of the summation of the factor loadings) + (square of the summation of the error variances);

b) Average Variance Extracted (AVE) $=$ (summation of the square of the factor loadings) / \{(summation of the square of the factor loadings) + (summation of the error variances)\}

Table 9 - Correlation matrix for the entire research constructs

\begin{tabular}{|l|r|r|r|r|}
\hline & \multicolumn{1}{|c|}{ SNE } & \multicolumn{1}{c|}{ SUS } & \multicolumn{1}{c|}{ SRNC } & \multicolumn{1}{c|}{ SRPV } \\
\hline SNE & 0.66 & & & \\
\hline SUS & 0.12 & 0.68 & & \\
\hline SRNC & 0.05 & 0.24 & 0.84 & \\
\hline SRPV & 0.43 & 0.18 & 0.43 & 0.72 \\
\hline
\end{tabular}

Note: $\mathrm{N}=62$; Numbers in parentheses are standard error; SNE = SEDeF and the national economy; SUS = Sustainability of SEDeF; SRNC = SEDeF and Residential Neighbourhood Crime; SRPV $=$ SEDeF and Residential Property Value

The main intention of the analyses is to build a measurement model that is adequately fit. From the foregoing, this has been achieved. The interpretation of this achievement is that the respondents (experts in related professions) in line with the measurement instruments adopted support the sustainability and desirability of socioenvironmental design factors (SEDeF) model as a veritable strategy for residential neighbourhood crime in Nigeria. The various aspects of the analysis supporting the result of the research include the reliability test (all above 0.7 ), normality test (all within the benchmark of -1 to +1 ), the cumulative mean of the constructs (all above 3.5) which indicates that the responses of the respondents were above average, the discriminant validity, convergence validity, correlation matrix and the fitted measurement model. The outcome of all these findings is that if the tenets of the model (SEDeF) could be tenaciously implemented, it would go a long way in curbing residential neighbourhood crime thereby enhancing a liveable housing environment which could translate to boosting housing investment as well as improved national economy.

\section{CONCLUSION}

From the research findings, it was statistically established that residential neighbourhood crime is transparently present within the Nigerian landscape [1] and that penal method of crime control strategies was prominent which existing studies had described to be grossly insufficient [22]. Hence, socio-environmental design factors (SEDeF) model was proposed as a better technique to the penal system. Consequently, from the responses of the various experts on the suitability and sustainability of SEDeF model as a veritable residential neighbourhood crime prevention alternative, which were statistically adjudged to be positive, it can therefore be asserted that the model is capable of effectively tackle residential neighbourhood crime as it is seen to be working in other countries like Canada, Australia, UK and USA where a replica of the model is in use.

Furthermore, in line with the results of this study, a clarion call is made on the various tiers of government in Nigeria to pay better attention to the social development programmes which have been described as the sure cure of the social risk factors like poverty, unemployment, illiteracy, homelessness, family disintegration and juvenile delinquencies to mention a few. Also, government needs to allow for a conducive environment that will enable workable and feasible residential layout design through site and services scheme. Developments on these schemes 
must be seen to comply with the building regulation to enhance the sustainability of the model. A tenacious implementation of the model is expected to result in value appreciation within the residential neighbourhoods, enhanced efficiency of labour, improved gross domestic product, housing sustainability, civil society, decrease in government annual budget on crime control and curbing psychological fear of crime which over time had resulted in sudden death of residents.

Conclusively, it is noteworthy that this study could not do enough justice to the deep comparison between penal system and SEDeF as well as delving into the key drivers of sustainability as they influence this proposed model. Future researches are set to bridge these research gaps.

\section{ACKNOWLEDGEMENTS}

This work was supported by the Universiti Tun Hussein Onn Malaysia (UTHM) and the Nigerian Tertiary Education Trust Fund (TETFund). The researchers express their invaluable gratitude to UTHM and TETFund for their support.

\section{REFERENCES}

1. Agbola T. (1997). The Architecture of Fear: Urban Design and Construction Response to Urban Violence in Lagos, Nigeria. Ibadan: IFRA, ABB.

2. Agunbiade, M. E. (2012). Land Administration for Housing Production (Doctoral thesis). Retrieved from

http://www.csdila.unimelb.edu.au/publication/theses/Muyiwa_LandAdministrationforhousing production.pdf

3. Awang, Z. (2015). SEM made simple: a gentle approach to learning structural equation modeling. Selangor: MPWS Rich Publication.

4. Awang, Z. (2014). A Handbook on Structural Equation Modeling. Selangor: MPWS Rich Publication.

5. Babin, B. J., Darden, W. R., \& Griffin, M. (1994). Work and/or fun: measuring hedonic and utilitarian shopping value. Journal of Consumer Research, 20(4), 644-656. doi: 10.1086/209376

6. Bentler, P. M. (1990). Comparative fit indexes in structural models. Psychological bulletin, 107(2), 238-246. doi: 10.1037//0033-2909.107.2.238

7. Bentler, P. M., \& Bonett, D. G. (1980). Significance tests and goodness of fit in the analysis of covariance structures. Psychological Bulletin, 88(3), 588-606. doi: 10.1037/0033-2909.88.3.588

8. Browne, M. W., \& Cudeck, R. (1993). Alternative ways of assessing model fit. Sociological Methods \& Research, 21(2), 230-258. doi: 10.1177/0049124192021002005

9. Cozens, P., Hillier, D., \& Prescott, G. (2001). Crime and the design of residential property - exploring the theoretical background - Part 1. Property management, 19(2), 136-164. doi: 10.1108/02637470110388235

10. David, M. \& Sutton, C. (2011). Social Research: An Introduction. London: SAGE Publications.

11. Fornell, C., \& Larcker, D. F. (1981). Evaluating structural equation models with unobservable variables and measurement error. Journal of Marketing Research, 18(1), 39-50. doi: $10.2307 / 3151312$

12. Gibbons, S. (2004). The costs of urban property crime*. The Economic Journal, 114(499), F441F463. doi: 10.1111/j.1468-0297.2004.00254.x

13. Hair, J. F., Ringle, C. M., \& Sarstedt, M. (2011). PLS-SEM: Indeed a silver bullet. The Journal of Marketing Theory and Practice, 19(2), 139-152. doi: 10.2753/mtp1069-6679190202

14. Kaiser, H. F. (1970). A second generation little jiffy. Psychometrika, 35(4), 401-415. doi: $10.1007 /$ bf02291817 
15. Marsh, H. W., and Hocevar, D. (1985). Application of confirmatory factor analysis to the study of self-concept: First-and higher order factor models and their invariance across groups. Psychological bulletin, 97(3), 562-582. doi: 10.1037/0033-2909.97.3.562

16. Marzbali, M. H., Abdullah, A., Ignatius, J., \& Tilaki, M. J. M. (2016). Examining the effects of crime prevention through environmental design (CPTED) on Residential Burglary. International Journal of Law, Crime and Justice, 46 (1), 86-102. doi: 10.1016/j.ijlcj.2016.04.001

17. Marzbali, M. H., Abdullah, A., Razak, N. A., \& Tilaki, M. J. M. (2012). Validating crime prevention through environmental design construct through checklist using structural equation modelling. International Journal of Law, Crime and Justice, 40(2), 82-99. doi: 10.1016/j.ijlcj.2011.08.005

18. Nor, A. R. M. (2009). Statistical Methods in Research. Petaling Jaya: Pearson Malaysia Sdn. Bhd.

19. Olajide, S. E., Lizam, M., \& Adewole A. (2015). Towards a Crime-free Housing: CPTED versus CPSD. Journal of Environment and Earth Science, 5(18), 53-63.

20. Pallant, J. (2010). SPSS Survival Manual (4th ed.). Maidenhead: McGraw-Hill.

21. Ross, A., Duckworth, K., Smith, D. J., Wyness, G., \& Schoon, I. (2011). Prevention and Reduction: A review of strategies for intervening early to prevent or reduce youth crime and anti-social behaviour (Research Report DFE-RR111). Retrieved from https://www.gov.uk/government/uploads/system/uploads/attachment_data/file/182548/DF E-RR111.pdf

22. Sutton, A., Cherney, A., \& White, R. (2013). Crime prevention: Principles, perspectives and practices. Port Melbourne; New York: Cambridge University Press.

23. The John Howard Society of Alberta. (1995). Crime Prevention Through Social Development: A Literature Review. Retrieved July 1, 2017, from http://www.johnhoward.ab.ca/pub/old/pdf/C6.pdf

24. Van Dijk, J. \& de Waard, J. (1991). A two dimensional typology of crime prevention projects: With a Bibliography. Criminal Justice Abstracts, 23, 483-503.

25. Waller, I., \& Weiler, D. (1985). Crime prevention through social development. Ottawa: Canadian Council on Social Development. 